\title{
Vasoactive Intestinal Peptide Promotes Corneal Allograft Survival
}

\author{
Vannarut Satitpitakul, ${ }^{* \dagger}$ Zhongmou Sun, ${ }^{*}$ Kunal Suri, ${ }^{*}$ Afsaneh Amouzegar, ${ }^{*}$ Kishore R. Katikireddy, ${ }^{*}$ Ula V. Jurkunas, ${ }^{*}$ \\ Ahmad Kheirkhah, * and Reza Dana*
}

From the Schepens Eye Research Institute, * Massachusetts Eye and Ear, Department of Ophthalmology, Harvard Medical School, Boston, Massachusetts; and the Department of Ophthalmology, ${ }^{\dagger}$ Faculty of Medicine, Chulalongkorn University and King Chulalongkorn Memorial Hospital, Bangkok, Thailand

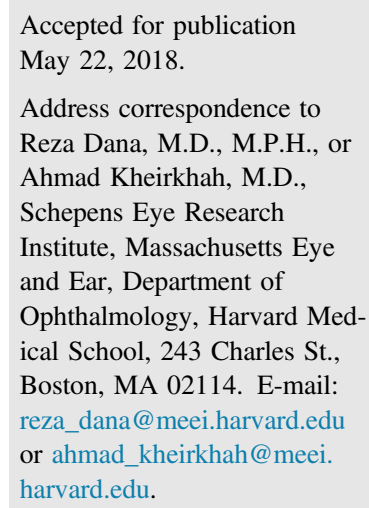

\begin{abstract}
Corneal transplantation is the most prevalent form of tissue transplantation. The success of corneal transplantation mainly relies on the integrity of corneal endothelial cells (CEnCs), which maintain graft transparency. CEnC density decreases significantly after corneal transplantation even in the absence of graft rejection. To date, different strategies have been used to enhance CEnC survival. The neuropeptide vasoactive intestinal peptide (VIP) improves CEnC integrity during donor cornea tissue storage and protects CEnCs against oxidative stress-induced apoptosis. However, little is known about the effect of exogenous administration of VIP on corneal transplant outcomes. We found that VIP significantly accelerates endothelial wound closure and suppresses interferon- $\gamma-$ and tumor necrosis factor- $\alpha$-induced CEnC apoptosis in vitro in a dose-dependent manner. In addition, we found that intracameral administration of VIP to mice undergoing syngeneic corneal transplantation with endothelial injury increases CEnC density and decreases graft opacity scores. Finally, using a mouse model of allogeneic corneal transplantation, we found for the first time that treatment with VIP significantly suppresses posttransplantation CEnC loss and improves corneal allograft survival. (Am J Pathol 2018, 188: 2016-2024; https://doi.org/10.1016/j.ajpath.2018.05.010)
\end{abstract}

Corneal transplantation is the most common form of tissue grafting worldwide. ${ }^{1}$ Most corneal transplants, which are performed in noninflamed and nonvascularized recipient beds, survive long term; however, graft survival substantially decreases in inflamed or vascularized host beds, so-called high-risk corneal transplantation., ${ }^{2,3}$ Successful outcome of corneal transplantation mainly relies on density and function of corneal endothelial cells (CEnCs), which keep the graft transparent. After corneal transplantation, even without an acute episode of immune rejection, $\mathrm{CEnC}$ density decreases significantly in the first 6 months, with a more gradual decrease afterward but with a rate that still exceeds the normal aging rate. ${ }^{4,5}$ Acute graft rejection is also associated with significant $\mathrm{CEnC}$ loss. ${ }^{6}$ Diminished density and function of CEnC below a crucial threshold can lead to irreversible graft failure. ${ }^{7,8}$

To improve the outcome of corneal transplantation, various strategies have been used to prevent immune-mediated graft rejection, such as use of immunosuppressive medications, antivascularization measures, HLA matching, and immune therapies. ${ }^{9,10}$ Furthermore, there has been an increasing interest in developing strategies to enhance survival and function of CEnCs. For this purpose, $\rho$ kinase inhibitors have been used in preclinical and clinical studies with promising results to increase CEnC migration. ${ }^{11-13}$ In addition, the neuropeptide vasoactive intestinal peptide (VIP) can preserve the integrity of $\mathrm{CEnCs}^{14-20}$ by maintaining the differentiated state of CEnCs and suppressing oxidative stress-induced CEnC apoptosis. ${ }^{15,21}$ Moreover, VIP enhances the preservation of CEnC integrity in donor corneas during storage, ${ }^{18-20}$ and silencing the expression of the VIP gene leads to deterioration of the hexagonal shape of CEnCs. ${ }^{17}$ VIP down-regulates the

Supported in part by the Eye Bank Association of America (A.K.), Eversight grant award (A.K.), the New England Cornea Transplant Fund (A.K.), the Harvard Cornea Center of Excellence Fellowship (A.K.), and the Massachusetts Lions Club (A.K., U.V.J., and R.D.).

Disclosures: Massachusetts Eye and Ear holds intellectual property pertaining to the use of VIP to prevent corneal endothelial cell loss (Patent Application Number 15/037,292); U.V.J. is listed as one of the inventors in the patent application. 
inflammatory potential of dying CEnCs. ${ }^{16}$ Despite the abovementioned evidence on the protective role of VIP for CEnCs, it remains unclear whether exogenous administration of VIP after corneal transplantation improves graft survival.

We hypothesized that the cytoprotective effects of VIP enhance CEnC survival in the corneal transplant setting, and thus its intracameral administration is associated with enhanced corneal graft survival. Accordingly, this study was designed to evaluate the in vitro and ex vivo effects of VIP on CEnCs as well as graft survival after corneal transplantation.

\section{Materials and Methods}

\section{CEnCs and Animals}

Human CEnCs (HCEnC-21Ts), immortalized by telomerase transduction, ${ }^{22}$ were courtesy of Dr. Ula Jurkunas (Schepens Eye Research Institute, Boston, MA). Eight-week-old $\mathrm{BALB} / \mathrm{c}$ and $\mathrm{C} 57 \mathrm{BL} / 6$ male mice were purchased from Charles River Laboratories (Wilmington, MA). The mice were housed in the animal vivarium of Schepens Eye Research Institute and treated according to the Association for Research in Vision and Ophthalmology statement for the Use of Animals in Ophthalmic and Vision Research. All animal procedures were approved by the Institutional Animal Care and Use Committee of Schepens Eye Research Institute.

\section{Wound Healing Assay of Cultured CEnCs}

HCEnC-21Ts (100,000 cells per well) were grown in the complete medium, which is composed of OptiMEM-I (Thermo Fisher Scientific, Waltham, MA) supplemented with $8 \%$ fetal bovine serum (Hyclone Laboratories Inc., Logna, UT), $5 \mathrm{ng} / \mathrm{mL}$ of epidermal growth factor (MilliporeSigma, Billerica, MA), $100 \mu \mathrm{g} / \mathrm{mL}$ of pituitary extract (Hyclone Laboratories Inc.), $0.2 \mathrm{mg} / \mathrm{mL}$ of calcium chloride (Sigma-Aldrich, St. Louis, MO), $0.08 \%$ chondroitin sulfate (Sigma-Aldrich), and 1\% antibiotic/antimycotic solution (Thermo Fisher Scientific), using six-well plates to reach a $90 \%$ confluent cell monolayer. The wound healing assay was used as a model to study the effect of VIP not on native corneal endothelium but rather on injured or damaged CEnCs that from a transplantation standpoint will not reach $100 \%$ confluency. Moreover, $90 \%$ confluent cells do not differ from $100 \%$ confluent cell monolayer in endothelial barrier and pump function as well as in the presence of zonula occludens protein 1 (ZO-1), Na/K-ATPase, and $\mathrm{N}$-cadherin. ${ }^{22}$ A scratch wound in the cell monolayer was created by scraping a straight line using a $200-\mu \mathrm{L}$ pipette tip. CEnCs were then incubated with different concentrations of VIP $\left(10^{-12}, 10^{-9}, 10^{-7}, 10^{-6} \mathrm{~mol} / \mathrm{L}\right)$ in Opti-MEM-I at $37^{\circ} \mathrm{C}$ with $5 \% \mathrm{CO}_{2}$. In the control group, no VIP was used. Wounded areas were monitored and imaged by fluorescence inverted microscope $(\times 50$ magnification;
Olympus IX51 with DP12; Olympus, Center Valley, PA) at $3,6,12$, and 24 hours of incubation. The percentage changes in wounded area from the baseline (wound healing rate) were analyzed using ImageJ version $1.49(\mathrm{NIH}$, Bethesda, MD; http://imagej.nih.gov/ij).

\section{Cornea-in-the-Cup Apoptosis Assay}

This experiment was performed to evaluate the effect of VIP on suppression of the CEnC apoptosis caused by proinflammatory cytokines interferon (IFN) $\gamma$ and tumor necrosis factor (TNF)- $\alpha$. To determine these effects, naïve C57BL/6 corneal cups cultured in RPMI 1640 medium with $10 \%$ fetal bovine serum and either $60 \mathrm{ng} / \mathrm{mL}$ of mouse IFN- $\gamma$ (Biolegend, San Diego, CA) or $50 \mathrm{ng} / \mathrm{mL}$ of mouse TNF- $\alpha$ (Biolegend) were incubated with three different concentrations of VIP $\left(10^{-12}, 10^{-9}, 10^{-6} \mathrm{~mol} / \mathrm{L}\right)$ in 96 -well plates for 18 hours in $5 \% \mathrm{CO}_{2}$ at $37^{\circ} \mathrm{C}$. In the control group, no VIP was used. After incubation, corneas were fixed in absolute ethanol for 20 minutes at room temperature. To determine apoptosis, corneas were stained with a conjugated ZO-1 antibody (1:200; Thermo Fisher Scientific) overnight at $4{ }^{\circ} \mathrm{C}$. The corneas were then washed and permeabilized with $0.1 \%$ Triton- $\mathrm{X}$ in $0.1 \%$ sodium citrate for 10 minutes at room temperature. Terminal deoxynucleotidyl transferase-mediated dUTP nick-end labeling (TUNEL) was performed using the In Situ Cell Death Detection Kit (Roche Diagnostics, Basel, Switzerland) according to the manufacturer's protocol. Two images were taken from the central part of each cornea using confocal microscopy ( $\times 400$ magnification; Leica TCS-SP5) and analyzed for percentage of $\mathrm{CEnC}$ apoptosis by dividing the total number of TUNEL-positive cells by the total number of ZO1 -positive cells counted by a masked observer using ImageJ software.

\section{Syngeneic Corneal Transplantation with Corneal Endothelial Injury Model}

Syngeneic corneal transplantation was performed using $\mathrm{BALB} / \mathrm{c}$ mice as both donor and host, similar to what has been described previously. ${ }^{23}$ The central cornea of donor mouse was excised into a 2-mm corneal button. The corneal endothelium and Descemet's membrane were then gently scraped and removed from the donor button using a $200-\mu \mathrm{L}$ pipette tip. Next, the donor button was stained with $0.4 \%$ Trypan blue solution (Sigma-Aldrich) for 10 seconds to confirm complete removal of corneal endothelium and Descemet's membrane. Subsequently, the donor button was transplanted into a $1.5-\mathrm{mm}$ excised host bed of the recipient mouse with eight interrupted 11-0 nylon sutures (AB-0550S; MANI, Tochigi, Japan). After surgery, host eyelids were closed for 1 day using 8-0 nylon sutures. Postoperatively, the mice were divided into two groups. In the VIP-treated group, the mice received intracameral injection of $5 \mu \mathrm{L}$ of $10^{-6} \mathrm{~mol} / \mathrm{L}$ VIP [(Sigma-Aldrich; diluted 
with sterile phosphate-buffered saline (PBS)] on days 1, 3, 5,7 , and 9 after surgery. The control group received $5 \mu \mathrm{L}$ of intracameral injection of sterile PBS with the same schedule. The mice were followed up for 6 weeks after transplantation. Interrupted corneal sutures were removed 7 days after surgery. Transplanted corneas were evaluated weekly by a masked observer using slit-lamp biomicroscopy to assess the corneal opacity with a standardized opacity grading system (range, 0 to $\geq 5$ ). ${ }^{24}$ Moreover, at weeks 2, 4, and 6 , some of the transplanted corneas $(n=4)$ were harvested for staining for ZO-1 and $\mathrm{Ki}-67$, as detailed below, to measure CEnC density and the percentage of Ki- $67^{+}$(proliferative) cells, respectively.

\section{High-Risk Allogeneic Corneal Transplantation}

High-risk allogeneic orthotopic corneal transplantation was performed as described previously. ${ }^{23,25}$ In brief, to induce inflamed and vascularized recipient beds, three intrastromal figure-of-eight suture knots were placed into the cornea of $\mathrm{BALB} / \mathrm{c}$ host mice using 11-0 nylon sutures 14 days before corneal transplantation. For transplantation, the $2-\mathrm{mm}$ central cornea was excised from a naïve C57BL/6 donor mouse and then grafted into a similarly prepared host bed of $1.5-\mathrm{mm}$ diameter in a BALB/c mouse. The donor button was secured with eight interrupted 11-0 nylon sutures onto the recipient bed. After surgery, host eyelids were closed for 1 day using 8-0 nylon sutures. Postoperatively, the mice were divided into two groups. In the VIP-treated group, the mice received intracameral injection of $10^{-6} \mathrm{~mol} / \mathrm{L}$ VIP as described above for the syngeneic transplantation. In the control group, $5 \mu \mathrm{L}$ of PBS was injected intracamerally with the same schedule. Corneal sutures were removed 7 days postoperatively, and the mice were followed up for 8 weeks after transplantation. After transplantation, the mice underwent weekly slit-lamp biomicroscopy to assess for corneal opacity as detailed above. Grafts with opacity scores of $>2$ (an opacity precluding clear recognition of iris details) for at least 2 consecutive weeks at a minimum of week 2 after transplantation were considered as failed grafts. Grafts that became opaque in the first 2 weeks after transplantation and never became clear were excluded from the survival analysis. Furthermore, at weeks 1, 2, and 8 after transplantation, some grafted corneas $(n=4)$ were harvested for ZO-1 and Ki-67 staining.

\section{Immunohistochemistry for Z0-1 and Ki-67}

At selected time points in both syngeneic and allogeneic transplantations, as detailed above, transplanted corneas were harvested and fixed with absolute ethanol for 20 minutes and washed three times with PBS at room temperature. Corneal endothelium was then permeabilized by incubation with $1 \%$ Triton X-100 (Sigma-Aldrich) in PBS for 20 minutes at room temperature. Corneas were stained with a conjugated ZO-1 antibody (1:200; Thermo Fisher
Scientific) and an anti-Ki-67 antibody (1:200; Abcam, Cambridge, MA) overnight at $4^{\circ} \mathrm{C}$. Corneas were then washed three times in PBS and incubated with rhodamine goat anti-rabbit IgG secondary antibody (1:200; Thermo Fisher Scientific). Flat mounts of the corneas were placed on glass slides with the endothelial layer facing up, and the endothelial cell-to-cell junctions and $\mathrm{Ki}-67^{+}$cells were visualized using confocal microscopy $(\times 400$ magnification; Leica TCS-SP5). Four images from the central part of each cornea were analyzed for CEnC density by dividing the total number of ZO-1-positive cells counted by the imaged area in a masked fashion using ImageJ software. Staining for ZO-1, cell-to-cell junction protein, was used to identify CEnC density rather than nuclear staining, such as DAPI, to avoid falsely increasing cell density because nuclear staining will also stain other cell types, such as immune cells and keratocytes.

\section{Statistical Analysis}

The $U$-test was used to compare percentage of CEnC apoptosis, graft opacity score, and CEnC density between the treated and control groups. The changes in CEnC density over time in each group were analyzed using Krukal-Wallis test. Kaplan-Meier analysis generated survival curves and respective log-rank tests compared the rates of corneal allograft survival. $P<0.05$ was considered statistically significant.

\section{Results}

\section{VIP Accelerates Human CEnC Wound Healing in Vitro}

The expression of the VIP receptor in cultured human CEnC and murine corneas was first confirmed using confocal microscopy (Supplemental Figure S1). To determine the effect of VIP on corneal endothelial wound healing, an in vitro wound model of cultured HCEnC-21T cells was incubated with $10^{-12}, 10^{-9}, 10^{-7}$, or $10^{-6} \mathrm{~mol} / \mathrm{L} \mathrm{VIP}$ (Figure 1). At 3 hours, the rates of wound healing in the control group and in VIP-treated cultures were $11.4 \%$ (control), $14.1 \%\left(10^{-12} \mathrm{~mol} / \mathrm{L} \mathrm{VIP}\right), 21.8 \%\left(10^{-9} \mathrm{~mol} / \mathrm{L}\right.$ VIP), $15.3 \%\left(10^{-7} \mathrm{~mol} / \mathrm{L} \mathrm{VIP}\right)$, and $6.2 \%\left(10^{-6} \mathrm{~mol} / \mathrm{L}\right.$ VIP). Statistically significant differences were found in wound healing rates between the control and $10^{-9}$ and $10^{-6} \mathrm{~mol} / \mathrm{L}$ VIP-treated cultures $(P=0.001$ and $P=0.01$, respectively). At 6 hours, the wound healing rates increased to $24.2 \%$ (control), $23.2 \%\left(10^{-12} \mathrm{~mol} / \mathrm{L} \mathrm{VIP}\right), 33.5 \%$ $\left(10^{-9} \mathrm{~mol} / \mathrm{L} \mathrm{VIP}\right), 26.7 \%\left(10^{-7} \mathrm{~mol} / \mathrm{L} \mathrm{VIP}\right)$, and $25.3 \%$ $\left(10^{-6} \mathrm{~mol} / \mathrm{L}\right.$ VIP $)$, with a statistically significant difference between the control and $10^{-9} \mathrm{~mol} / \mathrm{L}$ VIP group $(P=0.01)$. At 12 hours, wound healing rates increased to $41.0 \%$ (control), $34.6 \%\left(10^{-12} \mathrm{~mol} / \mathrm{L}\right.$ VIP), $57.3 \%\left(10^{-9} \mathrm{~mol} / \mathrm{L}\right.$ VIP), $58.3 \%\left(10^{-7} \mathrm{~mol} / \mathrm{L} \mathrm{VIP}\right)$, and $69.2 \%\left(10^{-6} \mathrm{~mol} / \mathrm{L}\right.$ VIP), and at 24 hours, $79.7 \%$ (control), $64.2 \%\left(10^{-12} \mathrm{~mol} / \mathrm{L}\right.$ VIP), $94.8 \%$ ( $\left.10^{-9} \mathrm{~mol} / \mathrm{L} \mathrm{VIP}\right), 93.9 \%\left(10^{-7} \mathrm{~mol} / \mathrm{L} \mathrm{VIP}\right)$, 

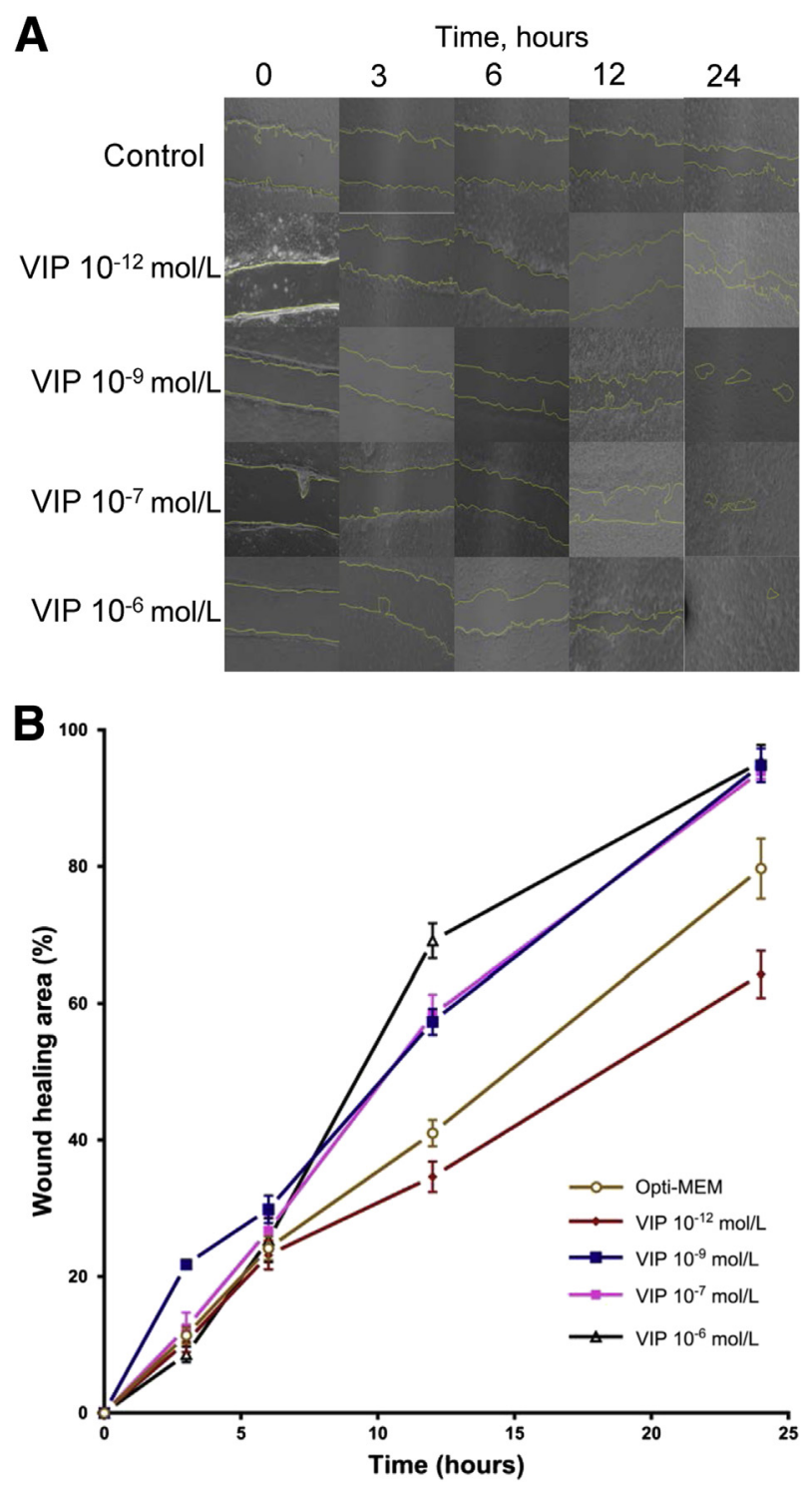

Figure 1 Vasoactive intestinal peptide (VIP) treatment of human corneal endothelial cells accelerates corneal endothelial wound healing in vitro in a dose-dependent manner. A: In vitro wound healing of cultured human corneal endothelial cells with or without VIP $\left(10^{-12}, 10^{-9}, 10^{-7}\right.$, $\left.10^{-6} \mathrm{~mol} / \mathrm{L}\right)$. Representative images show the remaining wounded area (yellow) in VIP-treated mice and in the control group (Opti-MEM) 3, 6, 12, and 24 hours after incubation. B: Percentage of healed endothelial area compared with baseline in VIP-treated groups and in controls. Human corneal endothelial cells treated with $10^{-9}, 10^{-7}$, and $10^{-6} \mathrm{~mol} / \mathrm{L}$ VIP demonstrate significantly enhanced wound healing compared with the control group 12 and 24 hours after incubation compared with the control $(P<0.05, U$-test). A dose-dependent trend was observed in the effect of VIP. Data are expressed as means \pm SEM and data from one of two independent experiments are shown (B). $n=9$. Original magnification, $\times 40$.

and $95.3 \%\left(10^{-6} \mathrm{~mol} / \mathrm{L}\right.$ VIP $)$ of wounded areas were healed. HCEnC-21Ts treated with $10^{-9}, 10^{-7}$, and $10^{-6}$ $\mathrm{mol} / \mathrm{L}$ VIP demonstrated significantly enhanced corneal endothelial wound closure compared with the control group at 12 and 24 hours after culture $(P=0.001, P=0.001$, and $P=0.004$ at 12 hours; $P=0.01, P=0.02$, and $P=0.03$ at 24 hours, respectively) (Figure 1).

\section{VIP Suppresses IFN- $\gamma-$ and TNF- $\alpha$-Induced CEnC Apoptosis ex Vivo}

Corneas co-cultured with IFN- $\gamma$ or TNF- $\alpha$ demonstrated significantly higher CEnC apoptosis (IFN- $\gamma$ group: $19.8 \% \pm 0.5 \%$; TNF $\alpha$ group: $16.7 \% \pm 2.6 \%$ ) compared with the corneas cultured in the media alone $(7.3 \% \pm 0.5 \%$; $P=0.02$ and $P=0.04$, respectively). Furthermore, a dosedependent trend was observed in the antiapoptotic effect of VIP against both IFN- $\gamma-$ and TNF- $\alpha-$ induced CEnC apoptosis. Corneas co-cultured with IFN- $\gamma$ supplemented with $10^{-12}, 10^{-9}$, and $10^{-6} \mathrm{~mol} / \mathrm{L}$ VIP showed $16.6 \% \pm 6.3 \%, 13.5 \% \pm 1.5 \%$, and $2.1 \% \pm 0.3 \%$ CEnC apoptosis, respectively. Supplementation of cultures with $10^{-6} \mathrm{~mol} / \mathrm{L}$ VIP significantly reduced IFN- $\gamma$-induced CEnC apoptosis $(P=0.02)$. Corneas co-cultured with TNF- $\alpha$ supplemented with $10^{-12}, 10^{-9}$, and $10^{-6} \mathrm{~mol} / \mathrm{L}$ VIP showed $11.3 \% \pm 3.3 \%, 8.7 \% \pm 2.3 \%$, and $0.9 \% \pm 0.3 \%$ CEnC apoptosis, respectively. Similarly, the percentage of CEnC apoptosis induced by TNF- $\alpha$ was significantly decreased on supplementation with $10^{-6} \mathrm{~mol} / \mathrm{L}$ VIP $(P=0.008)$ (Figure 2).

\section{VIP Treatment Decreases Corneal Graft Opacity and Accelerates CEnC Wound Healing in Murine Model of Syngeneic Corneal Transplantation with Endothelial Injury}

In syngeneic murine corneal transplantation with endothelial injury, corneal graft opacity scores were significantly lower in the VIP-treated group compared with the control group ( $P<0.05$ for weeks 2 to 6) (Figure 3, A and B). Although both VIP-treated and control groups had significantly increased densities over time $(P=0.002$ and $P=0.006$, respectively), CEnC density was significantly higher in the VIP-treated group compared with the control group at 4 weeks $\left(609 \pm 127\right.$ cells $/ \mathrm{mm}^{2}$ and $154 \pm 97$ cells $/ \mathrm{mm}^{2}$, respectively, $P=0.03$ ) and at 6 weeks after transplantation $\left(915 \pm 120\right.$ cells $/ \mathrm{mm}^{2}$ and $411 \pm 95$ cells $/ \mathrm{mm}^{2}$, respectively, $P=0.02$ ) (Figure 3, C and D). No Ki-67-positive cells were detected at any time points in either group.

\section{VIP Treatment Improves Allograft Survival and Preserves CEnC Density in High-Risk Corneal Transplantation}

In high-risk allogeneic murine corneal transplantation, graft opacity scores were significantly lower in the VIP-treated group compared with controls $(P<0.05$ for weeks 4 to 8$)$ (Figure 4A). In the VIP-treated group, $85 \%$ of the grafts survived by 8 weeks after transplantation, whereas all grafts in the control group were rejected by week 7 (hazard ratio, 0.10; 95\% CI, 0.04-0.26; $P<0.0001$ ) (Figure 4B).

The naïve corneas had a central (donor) CEnC density of $2886 \pm 21$ cells $/ \mathrm{mm}^{2}$. During 8 weeks of follow-up after 


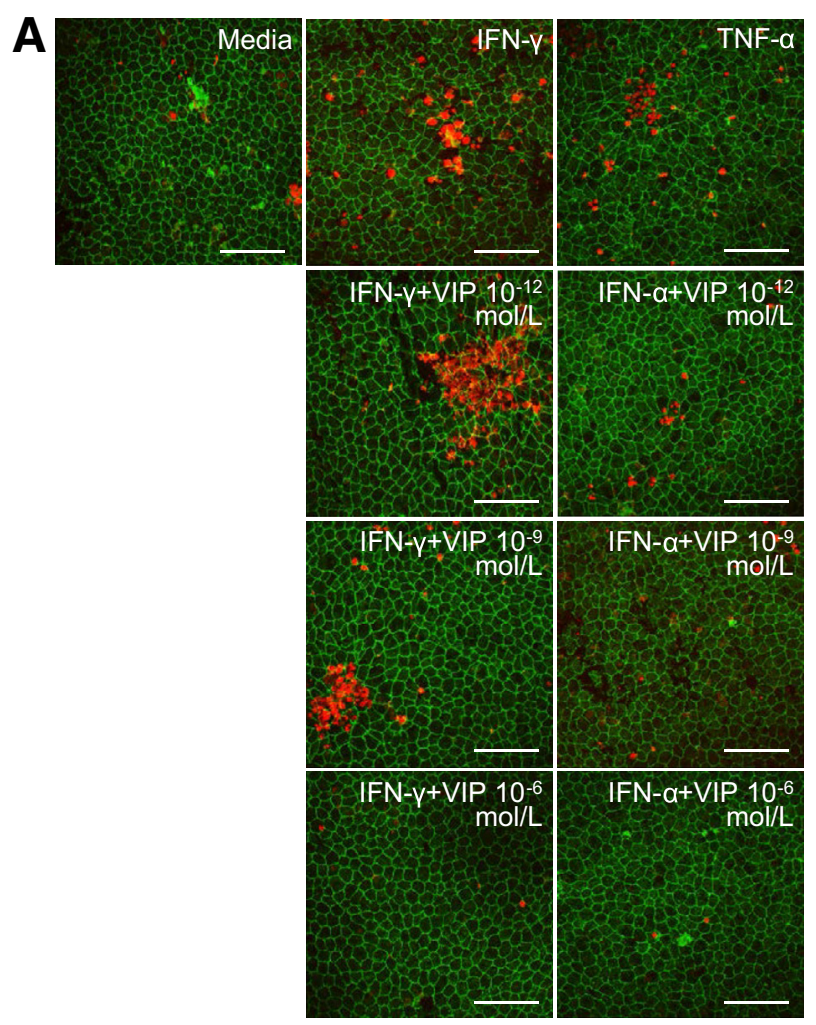

B

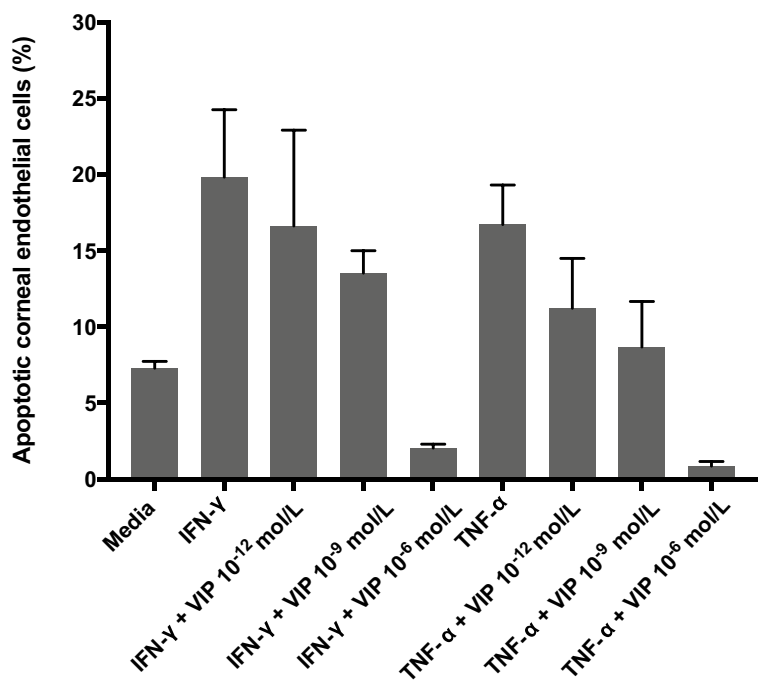

Figure 2 Vasoactive intestinal peptide (VIP) suppresses interferon (IFN)- $\gamma-$ and tumor necrosis factor (TNF)- $\alpha$-mediated corneal endothelial cell apoptosis. A: Representative confocal micrographs showing naïve $\mathrm{C} 57 \mathrm{BL} / 6$ corneal cups incubated with IFN- $\gamma$ or TNF- $\alpha$ with or without VIP $\left(10^{-12}, 10^{-9}, 10^{-6} \mathrm{~mol} / \mathrm{L}\right)$. After 18 hours of incubation, corneas were stained for zonula occluden-1 (green) and terminal deoxynucleotidyl transferase-mediated dUTP nick-end labeling assay (TUNEL, red) to visualize endothelial cell-to-cell junctions and apoptotic cells, respectively. B: Bar diagram showing the percentages of apoptotic (TUNEL-positive) corneal endothelial cells incubated ex vivo with IFN- $\gamma$ or TNF- $\alpha$ with different doses of VIP. VIP $10^{-6} \mathrm{~mol} / \mathrm{L}$ significantly suppresses IFN- $\gamma-$ and TNF- $\alpha$-mediated corneal endothelial cell apoptosis $[P=0.02$ and 0.008 , respectively (U-test)]. Data are expressed as means \pm SEM and data from one of two independent experiments are shown (B). $n=5$ corneas (B). Scale bars $=100 \mu \mathrm{m}$. Original magnification, $\times 400$. transplantation, the central CEnC density significantly decreased in both the VIP-treated and control groups $(P=0.02$ and $P=0.002$, respectively) (Figure 4, C and D). At 1 week after transplantation, central CEnC density was $2336 \pm 338$ cells $/ \mathrm{mm}^{2}$ in the VIP-treated group (19.0\% endothelial cell loss compared with naïve corneas) and $1221 \pm 226$ cells $/ \mathrm{mm}^{2}$ in the control group (57.7\% cell loss) $(P=0.11)$. At week 2 , although central CEnC density decreased to $782 \pm 166$ cells $/ \mathrm{mm}^{2}(72.6 \%$ cell loss) in the control group, VIP-treated corneas had significantly less $(23.1 \%)$ cell loss (CEnC density, $2192 \pm 247$ cells $\left./ \mathrm{mm}^{2} ; P=0.06\right)$. Similarly, VIP-treated corneas had significantly higher CEnC density at week 8 $\left(1436 \pm 104\right.$ cells $/ \mathrm{mm}^{2}, 48.9 \%$ cell loss $)$ compared with the control group $\left(206 \pm 87\right.$ cells $/ \mathrm{mm}^{2}, 92.7 \%$ cell loss; $P=0.02$ ) (Figure 4, C and D).

\section{Discussion}

This study found that exogenous administration of VIP suppresses inflammatory cytokine-induced $\mathrm{CEnC}$ apoptosis and enhances $\mathrm{CEnC}$ migration to the site of endothelial defect in both in vitro and in vivo models. Furthermore, exogenous application of VIP substantially improves graft survival in high-risk allogeneic corneal transplantation. Such a novel strategy may be used to improve outcomes of corneal transplantation in clinical trials.

VIP, a 28-amino acid neuropeptide, was first discovered in the gastrointestinal tract as a vasodilator. ${ }^{26}$ Since then, VIP has been recognized as an immunoregulatory and neuroprotective factor in various organ systems, including central and peripheral nervous systems. ${ }^{27,28}$ The therapeutic efficacy of VIP has been shown in several experimental models of autoimmune diseases. VIP has been demonstrated to down-regulate Th1 responses and to induce antigenspecific regulatory $\mathrm{T}$ cells and tolerogenic dendritic cells. $^{29,30}$ Furthermore, the direct cytoprotective effects of VIP in various types of cell injuries, such as hepatic ischemic-reperfusion injury, have been demonstrated. ${ }^{31,32}$ VIP also exerts protective effects against hypoxia-induced apoptotic death of lung alveolar cells and ameliorates reperfusion injury and improves pulmonary function in animal models of lung transplantation. ${ }^{33,34}$ In addition, VIP provides protection against neuronal cell death caused by $\beta$-amyloid- and dopamine-induced oxidative stress in neuronal cultures in experimental models of Alzheimer and Parkinson disease, respectively. ${ }^{35,36}$ In the eye, VIP binds the lacrimal gland, retina, choroid, ciliary processes, iris, conjunctiva, and cornea. ${ }^{37}$ In these sites, VIP causes different effects, such as increasing conjunctival goblet cell secretion, ${ }^{38}$ increasing protein secretion from lacrimal gland acinar cells, ${ }^{39}$ and preventing corneal stromal loss in the setting of alkali corneal injury. ${ }^{40} \mathrm{VIP}$ also increases aqueous humor outflow ${ }^{41}$ and contributes to the immunosuppressive activity of aqueous humor. ${ }^{42}$ 

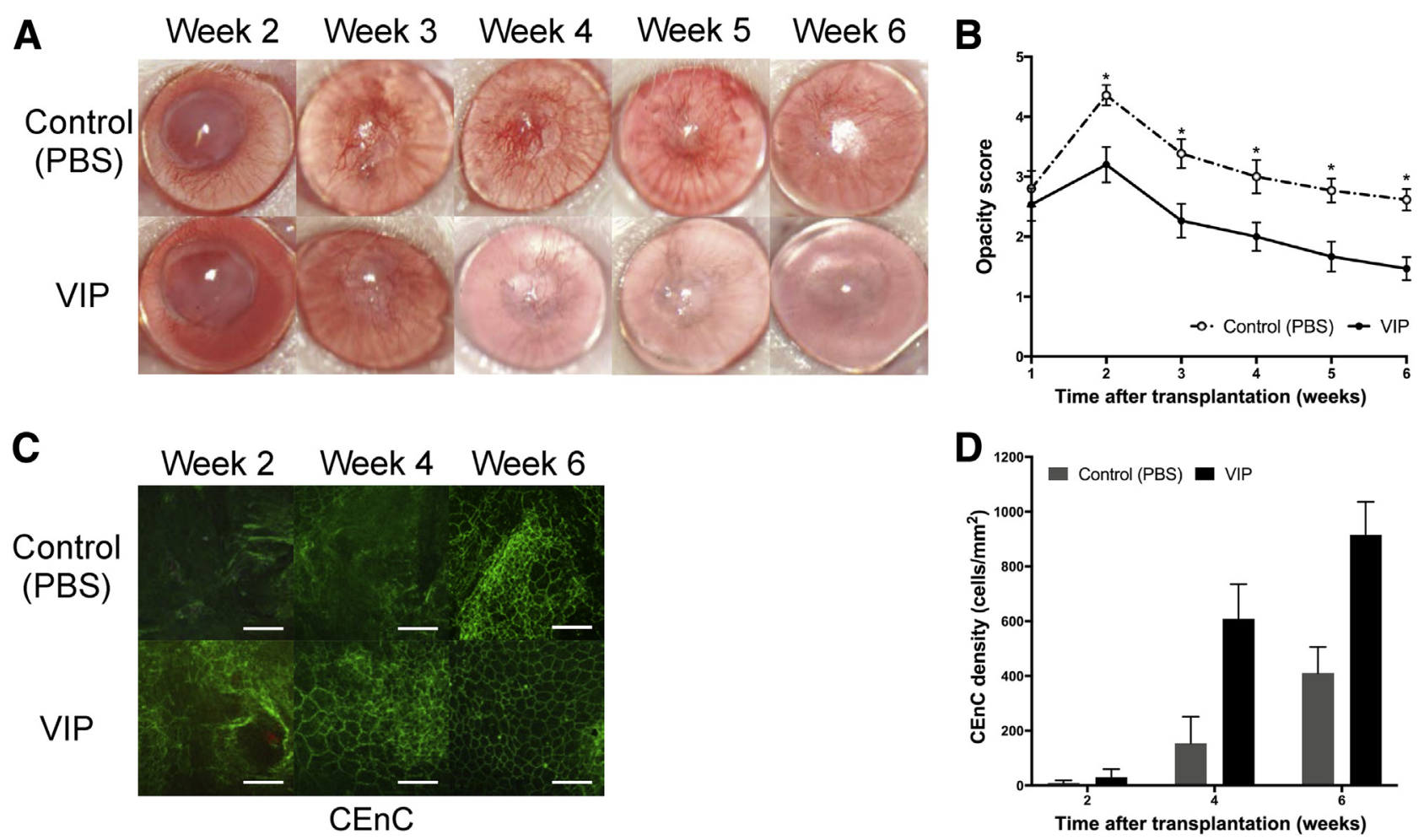

Figure 3 Vasoactive intestinal peptide (VIP) treatment decreases graft opacity and enhances corneal endothelial wound healing in a murine model of syngeneic corneal transplantation with endothelial injury. A: Representative slit-lamp images showing corneas at week 2 to 6 after transplantation. B: Graft opacity scores are significantly decreased in VIP-treated group from week 2 to 6 after transplantation compared with the control. C: Representative confocal micrographs of central area of transplanted corneas isolated from VIP-treated mice and the control groups at week 2, 4, and 6 after transplantation. To visualize corneal endothelial cell-to-cell junctions, corneas were stained with zonula occluden-1 (green). D: Bar diagram showing central corneal endothelial cell (CEnC) density in VIP-treated corneas compared with control at weeks 2, $4(P=0.03)$, and $6(P=0.02)$ post-after transplantation. Data are expressed as means \pm SEM and data from one of two independent experiments are shown. $n=6$ corneas (B); $n=15$ per group (B). ${ }^{*} P<0.05$ versus VIP (U-test). Scale bars $=100 \mu \mathrm{m}(\mathbf{C})$. Original magnification, $\times 25($ A) $; \times 400$ (C). PBS, phosphate-buffered saline.

There has also been a recent interest on the effects of VIP on CEnCs. ${ }^{14-20}$ With the use of immunohistochemical staining, the expression of VIPR1 was confirmed by both human and murine CEnCs. The source of VIP in aqueous humor is not known; however, the corneal endothelium has been suggested as a potential source. ${ }^{15}$ Furthermore, CEnCs are responsive to VIP modulation because this neuropeptide stimulates intracellular cAMP production in these cells in a dose- and time-dependent manner $^{14}$ and maintains the expression of the differentiation marker, $\mathrm{N}$-cadherin, in endothelial cells. ${ }^{17}$ VIP exerts antiapoptotic effects on CEnCs and protects these cells against the detrimental effects of oxidative stress. ${ }^{15,16}$ These studies have found that treatment of both fresh and preserved human donor corneoscleral tissue and precut corneas with VIP significantly prevents CEnC loss. ${ }^{14,15,19}$ However, despite the established beneficial effect of VIP in donor cornea eye banking, little is known about the effect of exogenous administration of this neuropeptide on CEnC wound healing and whether VIP can modulate CEnC resistance to proapoptotic effects of the proinflammatory cytokines IFN- $\gamma$ and TNF- $\alpha$ and affect corneal transplantation outcomes.
The corneal endothelium in human has limited proliferative potential in vivo, and thus endothelial wound healing is achieved by enlargement and migration of the remaining cells. ${ }^{43}$ Therefore, to evaluate functional effects of VIP on CEnCs, we investigated the effects of this neuropeptide on corneal endothelial wound healing in vitro using cultured human CEnCs. A dose-dependent trend was observed for concentrations of $10^{-9}$ to $10^{-12} \mathrm{~mol} / \mathrm{L}$ of VIP in enhancing endothelial healing. Such an effect, which is likely attributable to increased migration of these cells, was not seen for $10^{-12}-\mathrm{mol} / \mathrm{L}$ dose, which is the physiologic concentration of this neuropeptide in human aqueous humor, ${ }^{44}$ although it is not known whether the response of a CEnC line is similar to native cells in vivo. The proliferation of CEnC needs to be regulated in the physiologic state because unregulated CEnC proliferation can block the iridocorneal angle and disrupt the outflow of aqueous humor, which can lead to development of secondary glaucoma. ${ }^{45}$ The physiologic levels of VIP may be one of the factors that maintain the nonproliferative status of CEnCs in the steady state so that uncontrolled proliferation does not lead to new pathologic findings. 
A

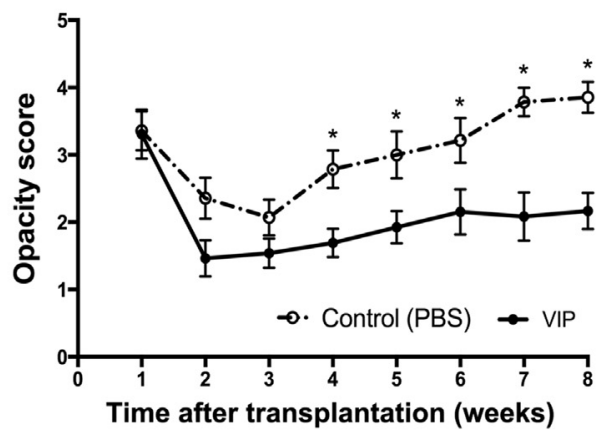

C

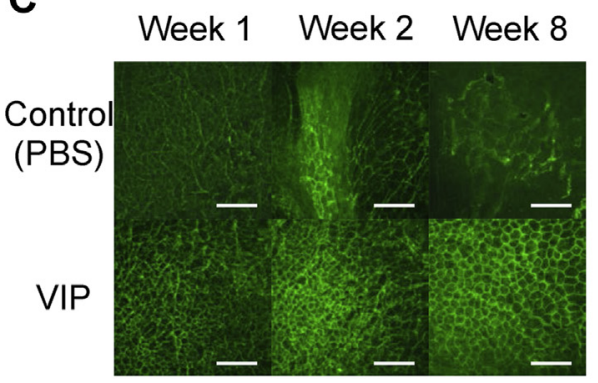

B
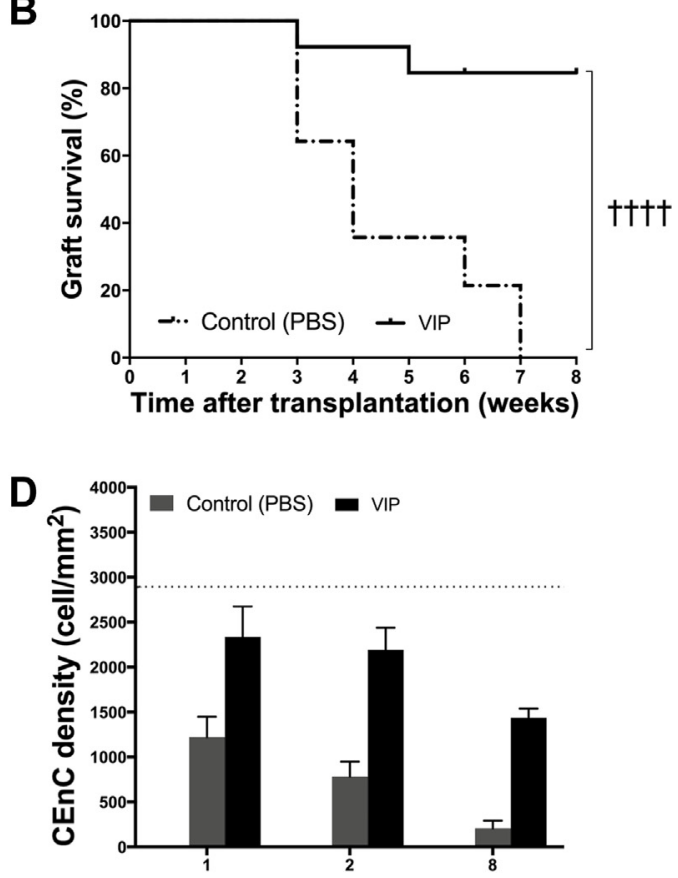

Time after transplantation (weeks)

Figure 4 Effect of vasoactive intestinal peptide (VIP) treatment on high-risk corneal transplant survival. Animals underwent high-risk allogeneic corneal transplantation and received treatment with VIP at 1, 3, 5, 7, and 9 days after transplantation. A: VIP treatment significantly decreases graft opacity scores at 4 to 8 weeks after transplantation. B: Weekly examination of grafts for 8 weeks demonstrates a significant increase in graft survival in VIP-treated mice compared with the controls ( $85 \%$ versus $0 \%$; hazard ratio, $0.10 ; 95 \%$ CI, 0.04-0.26). C: Representative confocal micrographs of central area of transplanted corneas in VIP-treated mice and in controls at 1,2, and 8 weeks after transplantation. Corneal endothelial cell-to-cell junction were stained and visualized with zonula occluden-1 (green). D: Bar diagram of central corneal endothelial cell (CEnC) densities show significantly higher CEnC density in the VIP-treated group compared with the controls at 8 weeks after transplantation $[P=0.02(U$-test)]. CEnC density in VIP-treated group did not reach statistical significance at weeks 1 and 2 after transplantation compared with the controls $(P=0.11$ and $P=0.06$, respectively). Horizontal dotted line represents the CEnC density of naïve age-matched $\mathrm{C} 57 \mathrm{BL} / 6$ corneas. Data are expressed as means \pm SEM and data from one out of two independent experiments are shown. $n=14$ (B); $n=5$ corneas (D). ${ }^{*} P<0.05$ versus VIP $\left(U\right.$-test) ${ }^{\dagger \dagger \dagger \dagger} P<0.0001$ (log-rank test). Scale bars $=100 \mu \mathrm{m}(\mathbf{C})$. Original magnification, $\times 400$ (C). PBS, phosphatebuffered saline.

It is well established that two main pathways for CEnC death include oxidative stress and inflammatory cytokines. ${ }^{46,47}$ In this study, the antiapoptotic effects of VIP were investigated for CEnCs against two proinflammatory cytokines, IFN- $\gamma$ and TNF- $\alpha$, which are major mediators of $\mathrm{CEnC}$ death in various conditions, including graft rejection. ${ }^{48-50}$ Notably, a dose-dependent antiapoptotic effect of VIP was observed on CEnCs against these cytokines. Such effects reached statistical significance in the $10^{-6}-\mathrm{mol} / \mathrm{L}$ dose, which also had the highest effect in enhancing endothelial wound healing. Previous studies on the effect of VIP treatment on CEnCs have linked the protective effect of VIP to the up-regulation of antiapoptotic Bcl-2 mRNA and increased levels of the CEnC differentiation marker, N-cadherin. ${ }^{16,17} \mathrm{CEnC}$ apoptosis induced by proinflammatory cytokines, however, is not fully suppressed by VIP administration, which suggests that other factors, such as mechanical injury during surgery, can also induce CEnC loss. Because IFN- $\gamma$ and TNF- $\alpha$ contribute to CEnC death after corneal transplantation, ${ }^{48-50}$ the effects of exogenous application of VIP were evaluated on the outcome of corneal transplantation.
VIP exerts various immunomodulatory functions and down-regulates immune cell-mediated responses, which may play a role in the immune privilege status of the anterior chamber. ${ }^{42,51,52}$ Thus, any potential effect of this neuropeptide on outcomes of corneal transplantation may be attributable to these immunomodulatory effects rather than its direct effect on CEnC survival. To demonstrate the direct cytoprotective effects of VIP on CEnC, the effect of exogenous administration of VIP was evaluated in a syngeneic murine corneal transplant model, which circumvents allospecific immune responses. Furthermore, to evaluate effects of VIP on migration of CEnCs from the recipient bed to the graft, an injury model, in which the whole endothelium and Descemet's membrane were mechanically removed from the donor cornea before transplantation, was used. This is different from previous in vivo methods in which cryotherapy, chemical injury, or YAG laser have been used, which are associated with significant corneal inflammation. ${ }^{53-55}$ With the use of this model in syngeneic corneal grafting, intracameral injection of $10^{-6} \mathrm{~mol} / \mathrm{L}$ VIP after transplantation led to a significant decrease in graft opacity scores compared with the control group of only PBS injection. Moreover, the VIP-treated group had a 
significantly higher central CEnC density starting from week 4 after transplantation.

Because human corneal transplantation is allogeneic, the effect of exogenous administration of VIP was evaluated on the graft outcomes in a high-risk murine corneal transplantation. Such high-risk corneal grafting is associated with a high rate of graft rejection and subsequent failure attributable to endothelial cell loss and decompensation. ${ }^{10,56}$ Administration of VIP after transplantation in this high-risk model was associated with a significant decrease in graft opacity scores and a significant increase in long-term corneal allograft survival (85\% versus $0 \%$ at week 8). The main mechanism of graft protection in this context is likely related to the antiapoptotic effects of VIP, which helps maintain CEnCs. Furthermore, although in both groups central CEnC density decreased over time, the cell loss at 8 weeks was significantly lower in the VIP-treated group compared with the control group. In the murine model of allogeneic corneal transplantation, it has been observed that $30 \%$ to $40 \%$ of CEnCs are rapidly lost during the first 48 hours after transplantation. ${ }^{56,57}$ Similarly, the data indicate a rapid decrease in $\mathrm{CEnC}$ central density in the early posttransplantation period. The data in allogeneic transplantation also demonstrate that CEnC loss after transplantation can be significantly suppressed by VIP administration. In this study, VIP was injected into the anterior chamber as a proof of concept study to ensure the local delivery of VIP to CEnCs that line the inside of the corneal graft. However, the optimal method and frequency of VIP delivery need to be further studied in the future.

There are several limitations to the current study. First, data from immortalized and murine cells cannot necessarily be translated to cell function in vivo. Second, the study focused on CEnC response to injury and corneal graft clarity, which is affected by but not synonymous with cell pump function. Third, many neuropeptides, including VIP, have pleotropic functions based on their tissue levels. Thus, data from these studies cannot directly be translated to optimal dosage for therapeutic applications in humans. Fourth and relatedly, additional work needs to be performed in regard to potential toxic effects before this approach can be translated to the clinical setting.

In summary, in vitro and in vivo data demonstrate for the first time that exogenous administration of VIP is associated with higher retention of central CEnC density and enhanced corneal graft survival. These data, in conjunction with previous data demonstrating enhanced preservation of stored donor tissue CEnCs, ${ }^{15,19}$ suggest that neuropeptide use may provide a new strategy for enhancing eye banking and graft outcomes in corneal transplantation for both penetrating and endothelial lamellar keratoplasty. As noted above, additional investigations focused on dosing, toxic effects, and pump function need to be completed before translation to the clinical setting.

\section{Supplemental Data}

Supplemental material for this article can be found at https://doi.org/10.1016/j.ajpath.2018.05.010.

\section{References}

1. Gain P, Jullienne R, He Z, Aldossary M, Acquart S, Cognasse F, Thuret G: Global survey of corneal transplantation and eye banking. JAMA Ophthalmology 2016, 134:167-173

2. Niederkorn JY: The immune privilege of corneal allografts. Transplantation 1999, 67:1503-1508

3. The Collaborative Corneal Transplantation Studies Research Group: The collaborative corneal transplantation studies (CCTS): effectiveness of histocompatibility matching in high-risk corneal transplantation. Arch Ophthalmol 1992, 110:1392-1403

4. Obata H, Ishida K, Murao M, Miyata K, Sawa M: Corneal endothelial cell damage in penetrating keratoplasty. Jpn J Ophthalmol 1991, 35: 411-416

5. Acar BT, Vural ET, Acar S: Changes in endothelial cell density following penetrating keratoplasty and deep anterior lamellar keratoplasty. Int Journal Ophthalmol 2011, 4:644-647

6. Musch DC, Schwartz AE, Fitzgerald-Shelton K, Sugar A, Meyer RF: The effect of allograft rejection after penetrating keratoplasty on central endothelial cell density. Am J Ophthalmol 1991, 111: 739-742

7. Claerhout I, Beele H, Kestelyn P: Graft failure, I: endothelial cell loss. Int Ophthalmol 2008, 28:165-173

8. Patel SV, Hodge DO, Bourne WM: Corneal endothelium and postoperative outcomes 15 years after penetrating keratoplasty. Am J Ophthalmol 2005, 139:311-319

9. Di Zazzo A, Kheirkhah A, Abud TB, Goyal S, Dana R: Management of high-risk corneal transplantation. Surv Ophthalmol 2017, 62 : $816-827$

10. Amouzegar A, Chauhan SK, Dana R: Alloimmunity and tolerance in corneal transplantation. J Immunol 2016, 196:3983-3991

11. Okumura N, Ueno M, Koizumi N, Sakamoto Y, Hirata K, Hamuro J, Kinoshita S: Enhancement on primate corneal endothelial cell survival in vitro by a ROCK inhibitor. Invest Ophthalmol Vis Sci 2009, $50: 3680-3687$

12. Okumura N, Kinoshita S, Koizumi N: Application of Rho kinase inhibitors for the treatment of corneal endothelial diseases. J Ophthalmol 2017, 2017:2646904

13. Nakagawa H, Koizumi N, Okumura N, Suganami H, Kinoshita S: Morphological changes of human corneal endothelial cells after Rhoassociated kinase inhibitor eye drop (Ripasudil) administration: a prospective open-label clinical study. PLoS One 2015, 10:e0136802

14. Koh SW, Yue BY: VIP stimulation of cAMP production in corneal endothelial cells in tissue and organ cultures. Cornea 2002, 21 : 270-274

15. Koh SW, Waschek JA: Corneal endothelial cell survival in organ cultures under acute oxidative stress: effect of VIP. Invest Ophthalmol Vis Sci 2000, 41:4085-4092

16. Koh SW, Cheng J, Dodson RM, Ku CY, Abbondandolo CJ: VIP down-regulates the inflammatory potential and promotes survival of dying (neural crest-derived) corneal endothelial cells ex vivo: necrosis to apoptosis switch and up-regulation of Bcl-2 and $\mathrm{N}$-cadherin. J Neurochem 2009, 109:792-806

17. Koh SW, Chandrasekara K, Abbondandolo CJ, Coll TJ, Rutzen AR: VIP and VIP gene silencing modulation of differentiation marker $\mathrm{N}$-cadherin and cell shape of corneal endothelium in human corneas ex vivo. Invest Ophthalmol Vis Sci 2008, 49:3491-3498

18. Koh SW: Corneal endothelial autocrine trophic factor VIP in a mechanism-based strategy to enhance human donor cornea preservation for transplantation. Exp Eye Res 2012, 95:48-53 
19. Koh SM, Coll T, Gloria D, Sprehe N: Corneal endothelial cell integrity in precut human donor corneas enhanced by autocrine vasoactive intestinal peptide. Cornea 2017, 36:476-483

20. Koh SW, Gloria D, Molloy J: Corneal endothelial autocrine VIP enhances its integrity in stored human donor corneoscleral explant. Invest Ophthalmol Vis Sci 2011, 52:5632-5640

21. Koh SW, Guo Y, Bernstein SL, Waschek JA, Liu X, Symes AJ: Vasoactive intestinal peptide induction by ciliary neurotrophic factor in donor human corneal endothelium in situ. Neurosci Lett 2007, 423: 89-94

22. Schmedt T, Chen Y, Nguyen TT, Li S, Bonanno JA, Jurkunas UV: Telomerase immortalization of human corneal endothelial cells yields functional hexagonal monolayers. PLoS One 2012, 7:e51427

23. Dana MR, Yamada J, Streilein JW: Topical interleukin 1 receptor antagonist promotes corneal transplant survival. Transplantation 1997, 63:1501-1507

24. Sonoda Y, Streilein JW: Orthotopic corneal transplantation in mice-evidence that the immunogenetic rules of rejection do not apply. Transplantation 1992, 54:694-704

25. Inomata T, Mashaghi A, Di Zazzo A, Dana R: Ocular surgical models for immune and angiogenic responses. J Biol Methods 2015, 2. e27

26. Said SI, Mutt V: Polypeptide with broad biological activity: isolation from small intestine. Science 1970, 169:1217-1218

27. Moody TW, Hill JM, Jensen RT: VIP as a trophic factor in the CNS and cancer cells. Peptides 2003, 24:163-177

28. Said SI, Rosenberg RN: Vasoactive intestinal polypeptide: abundant immunoreactivity in neural cell lines and normal nervous tissue. Science 1976, 192:907-908

29. Souza-Moreira L, Delgado-Maroto V, Delgado M: Potential applications of vasoactive intestinal peptide-based therapies on transplantation. Endocr Metab Immune Disord Drug Targets 2012, 12: $333-343$

30. Mathioudakis A, Chatzimavridou-Grigoriadou V, Evangelopoulou E, Mathioudakis G: Vasoactive intestinal peptide inhaled agonists: potential role in respiratory therapeutics. Hippokratia 2013, 17:12-16

31. Ji H, Zhang Y, Liu Y, Shen XD, Gao F, Nguyen TT, Busuttil RW, Waschek JA, Kupiec-Weglinski JW: Vasoactive intestinal peptide attenuates liver ischemia/reperfusion injury in mice via the cyclic adenosine monophosphate-protein kinase a pathway. Liver Transpl 2013, 19:945-956

32. Jiang W, Tang W, Geng Q, Xu X: Inhibition of Toll-like receptor 4 with vasoactive intestinal peptide attenuates liver ischemiareperfusion injury. Transplant Proc 2011, 43:1462-1467

33. Nagahiro I, Yano M, Boasquevisque CH, Fujino S, Cooper JD, Patterson GA: Vasoactive intestinal peptide ameliorates reperfusion injury in rat lung transplantation. J Heart Lung Transplant 1998, 17: 617-621

34. Ao X, Fang F, Xu F: Vasoactive intestinal peptide protects alveolar epithelial cells against hyperoxia via promoting the activation of STAT3. Regul Pept 2011, 168:1-4

35. Gozes I, Bardea A, Reshef A, Zamostiano R, Zhukovsky S, Rubinraut S, Fridkin M, Brenneman DE: Neuroprotective strategy for Alzheimer disease: intranasal administration of a fatty neuropeptide. Proc Natl Acad Sci U S A 1996, 93:427-432

36. Offen D, Sherki Y, Melamed E, Fridkin M, Brenneman DE, Gozes I: Vasoactive intestinal peptide (VIP) prevents neurotoxicity in neuronal cultures: relevance to neuroprotection in Parkinson's disease. Brain Res 2000, 854:257-262

37. Denis P, Dussaillant M, Nordmann JP, Elena PP, Saraux H, Rostene W: Autoradiographic characterization and localization of vasoactive intestinal peptide binding sites in albino rat and rabbit eyes. Exp Eye Res 1991, 52:357-366
38. Dartt DA, Kessler TL, Chung EH, Zieske JD: Vasoactive intestinal peptide-stimulated glycoconjugate secretion from conjunctival goblet cells. Exp Eye Res 1996, 63:27-34

39. Adeghate EA, Singh J, Howarth FC, Burrows S: Control of porcine lacrimal gland secretion by non-cholinergic, non-adrenergic nerves: effects of electrical field stimulation, VIP and NPY. Brain Res 1997, 758:127-135

40. Tuncel N, Yildirim N, Gurer F, Basmak H, Uzuner K, Sahinturk V, Gursoy $\mathrm{H}$ : Effect of vasoactive intestinal peptide on the wound healing of alkali-burned corneas. Int J Ophthalmol 2016, 9:204-210

41. Mittag TW, Tormay A, Podos SM: Vasoactive intestinal peptide and intraocular pressure: adenylate cyclase activation and binding sites for vasoactive intestinal peptide in membranes of ocular ciliary processes. J Pharmacol Exp Ther 1987, 241:230-235

42. Taylor AW, Streilein JW, Cousins SW: Immunoreactive vasoactive intestinal peptide contributes to the immunosuppressive activity of normal aqueous humor. J Immunol 1994, 153:1080-1086

43. Kaufman HE, Capella JA, Robbins JE: The human corneal endothelium. Am J Ophthalmol 1966, 61:835-841

44. Koh SW, Rutzen A, Coll T, Hemady R, Higginbotham E: VIP immunoreactivity in human aqueous humor. Curr Eye Res 2005, 30: 189-194

45. Silva L, Najafi A, Suwan Y, Teekhasaenee C, Ritch R. The iridocorneal endothelial syndrome. Surv Ophthalmol 2018, [Epub ahead of print] doi:10.1016/j.survophthal.2018.01.001

46. Matthaei M, Zhu AY, Kallay L, Eberhart CG, Cursiefen C, Jun AS: Transcript profile of cellular senescence-related genes in Fuchs endothelial corneal dystrophy. Exp Eye Res 2014, 129:13-17

47. Hu J, Kovtun A, Tomaszewski A, Singer BB, Seitz B, Epple M, Steuhl KP, Ergun S, Fuchsluger TA: A new tool for the transfection of corneal endothelial cells: calcium phosphate nanoparticles. Acta Biomater 2012, 8:1156-1163

48. Sagoo P, Chan G, Larkin DF, George AJ: Inflammatory cytokines induce apoptosis of corneal endothelium through nitric oxide. Invest Ophthalmol Vis Sci 2004, 45:3964-3973

49. Lahdou I, Engler C, Mehrle S, Daniel V, Sadeghi M, Opelz G, Terness P: Role of human corneal endothelial cells in T-cell-mediated alloimmune attack in vitro. Invest Ophthalmol Vis Sci 2014, 55:1213-1221

50. Nicholls SM, Banerjee S, Figueiredo FC, Crome S, Mistry S, Easty DL, Dick AD: Differences in leukocyte phenotype and interferon-gamma expression in stroma and endothelium during corneal graft rejection. Exp Eye Res 2006, 83:339-347

51. Sabatino F, Di Zazzo A, De Simone L, Bonini S: The intriguing role of neuropeptides at the ocular surface. Ocul Surf 2017, 15:2-14

52. Delgado M, Ganea D: Vasoactive intestinal peptide: a neuropeptide with pleiotropic immune functions. Amino Acids 2013, 45:25-39

53. Han SB, Ang H, Balehosur D, Peh G, Chaurasia SS, Tan DT, Mehta JS: A mouse model of corneal endothelial decompensation using cryoinjury. Mol Vis 2013, 19:1222-1230

54. ElKitkat RS, Ebeid WM, Habib EK, Shoukry Y: Safety of intracameral injection of minimal bactericidal concentration of povidone iodine on the corneal endothelium in a rabbit model. Cornea 2016, 35:72-76

55. Zhang W, Hu Y, Lu L, Liu Y, Yang X, Sun H, Ruan J, Chen J, Yao Q, Yan C, Gu P, Fu Y, Shao C, Fan X: Rabbit model of corneal endothelial injury established using the Nd: YAG laser. Cornea 2017, 36:1274-1281

56. Chauhan SK, Jurkunas U, Funaki T, Dastjerdi M, Dana R: Quantification of allospecific and nonspecific corneal endothelial cell damage after corneal transplantation. Eye (Lond) 2015, 29:136-144

57. Plskova J, Kuffova L, Filipec M, Holan V, Forrester JV: Quantitative evaluation of the corneal endothelium in the mouse after grafting. Br J Ophthalmol 2004, 88:1209-1216 